\title{
Creep and High-Temperature Deformation of Metals and Alloys
}

\author{
Elisabetta Gariboldi ${ }^{1, *(\mathbb{D})}$ and Stefano Spigarelli ${ }^{2, *}$ \\ 1 Politecnico di Milano, Dipartimento di Meccanica, Via La Masa 1, 20156 Milano, Italy \\ 2 Department of Industrial Engineering and Mathematical Sciences, Marche Polytechnic University, \\ Via Brecce Bianche, 60131 Ancona, Italy \\ * Correspondence: elisabetta.gariboldi@polimi.it (E.G.); s.spigarelli@staff.univpm.it (S.S.); \\ Tel.: +39-02-2399-8224 (E.G.); +39-071-220-4746 (S.S.)
}

Received: 29 September 2019; Accepted: 5 October 2019; Published: 10 October 2019

\section{Introduction and Scope}

The occurrence of time-dependent deformation of metals and alloys under constant loads or stresses, a phenomenon termed "creep", has been documented for at least two centuries. Yet, its real significance was appreciated only by the late 1940s, when some peculiar features of creep, such as the occurrence of plastic deformation under stresses well below yielding, were investigated in detail.

The continuous development of dislocation theories later enlightened some specific features of creep deformation and gave the basis for correlating the macroscopic creep properties to the time-dependent processes taking place within the metals and alloys. Similarly, the same dislocation theories were used to provide a physical background to the study of metals' and alloys' responses to hot working processes. Stress relaxation effects were also explained and modelled on similar bases.

While progressively more defined experimental and theoretical studies of the creep and hot working process mechanism were carried out, new creep-resistant materials have been developed and/or explained based on the abovementioned microstructure-mechanical behavior correlations. Similarly, new hot-working techniques have been introduced.

Notwithstanding that the mechanisms that control creep and hot working are essentially the same, advances in creep-resistant material and in hot working processes have often proceeded independently. The title the Editors selected for the Special Issue of Metals_-"Creep and High-Temperature Deformation of Metals and Alloys"-underline common features between them.

\section{Contributions to the Special Issue}

Scholars have been invited to submit research papers dealing with innovative research and literature surveys on specific aspects of creep and high-temperature deformation so that the readers could realize the common points between them. Among the submitted manuscripts, 14 papers have been published in the issue.

\subsection{Creep Deformation, Damage, and Ductility}

Creep deformation mechanisms are typically described in terms of secondary creep strain rate. A good description of strain rate dependences over large temperature and applied stress values, taking into account compositional or microstructural effects, corresponds to a good understanding of the phenomena taking place at a microscopical level and leading to deformation. These general features have been considered in the issue both in the works by Delandar et al. [1] and by Kassner [2] Delandar et al. specifically refer to copper and to its deformation mechanisms when creep deformation occurs at relatively low temperatures (up to $100{ }^{\circ} \mathrm{C}$ ). Its deformation behavior has been modelled and 
verified both by experimental data and by Dynamic Dislocation simulations. The work by Kassner [2] suggests that the five-power-law creep can be applied in the case of alloys with pure metal behavior (class $\mathrm{M}$ alloys) by considering a linear superposition of a dislocation hardening term and a solute strengthening term.

Creep damage phenomena of different kinds lead material to creep rupture, with more or less accumulation of plastic deformation and with different fracture modes, depending on materials and test (or service) temperature and stress conditions. Some of the published papers deal with creep damage. In many high-temperature alloys, creep damage is due to the grain boundary cavitation, and modelling of its evolution up to the final rupture can be very important. Xu et al. contributed a paper [3] in which FE simulation of grain boundary cavitation helped understanding the role played by stress redistribution, cavitation damage, and creep fracture. Creep damage evolution can also be carefully modelled by innovative combinations of experimental investigation techniques, such as small-angle neutron scattering (SANS), scanning electron microscopy, and quantitative metallography, as reported by Jazeri et al. in [4] in the case of a 304 stainless steel. The effects of prior residual stress left by welding processes on the damage at the crack tip of a 9-12\% Cr steel specimen with simulated weldment was investigated experimentally by Liu et al. [5], who observed residual stress-related transition of damage forms.

The creep ductility of steels, related to the strain that can be accumulated at material rupture, is the topic of a review paper by Holdsworth [6]. A set of features involving creep ductility of high-temperature steels, including acritical analysis of creep ductility data, can be applied to predict long-term ductility exhaustion in multi-temperature and multi-cast data sets. Furthermore, the creep ductility of steels can be analyzed in cases of stress multiaxiality.

\subsection{Innovative Testing Techniques of Creep Deformation}

Within decades, new experimental techniques have been introduced to investigate the creep properties of materials in specific cases, for example, related to the small size of the available material from which specimens should be sampled. An example is illustrated in the work by Glee et al. [7] where, in order to avoid any influence from the substrate, miniaturized cylindrical tensile specimens of bond coatings were produced by a special grinding process, exposed to different environments and then creep tested. On the other hand, Ding et al. [8] focused on the nanoindentation technology, also suitable for small material regions characterization. The technique has been used in [8], using both a Berkovich and a spherical indenter, on a Zr-based bulk metallic glass to investigate its creep behaviour at room temperature and to evaluate at the same time the effects of testing parameters.

\subsection{Creep and Hot Deformation Interacting in the Presence of Loading/Temperature Changes and Environmental Effects}

Creep deformation phenomena often do not operate under the conventional constant-temperature/ constant-stress force under which conventional creep characterization of materials is carried out. In fact, in industrial applications, materials can operate under different loading or temperature conditions where phenomena like creep-buckling and creep-fatigue can significantly affect the material deformation, microstructural and damage evolution, and final fracture with respect to its behaviour under conventional testing conditions. In the present issue of Metals, these features have been introduced and applied to representative and widely diffused steels, such as the austenitic stainless steel 304, for which buckling phenomena have been investigated by Jo et al. [9] in the specific case of tubes subjected to radial external pressure load in the temperature range of $800-1000{ }^{\circ} \mathrm{C}$. Jürgens et al. [10] have investigated the low-cycle fatigue and relaxation phenomena for the P92 steel, a representative $9-12 \%$ Cr ferritic-martensitic steel. 


\subsection{Creep-Microstructure Correlations for Specific Material Classes}

The strict correlations between microstructure of metals and alloys and their creep and hot deformation processes have always been of interest in the creep research field, due to practical industrial request for increasingly creep-resistant materials. This topic has also been covered in the papers included in the present Special Issue of Metals. One group of papers focuses on the widespread class of ferritic-martensitic steels.

The paper by $\mathrm{Wu}$ et al. [11] deals with the effect of heat treatment process parameters, and specifically the normalizing temperature, in grade 91 , a 9-12\% Cr steel, which is discussed on the basis of a careful microstructural analysis of crept samples. Other critical features for the industrial applications of these steels have been considered in the Issue, such as weld joint behaviour (Hu et al. [5] investigated the effect of residual stresses left by these processes on creep damage) or creep-fatigue and creep relaxation phenomena (Jürgens et al. [10]).

The strict correlation between microstructural features is also of utmost importance for the development and application of other high-temperature alloys. Moving to steels and Ni-based alloys characterized by an austenitic matrix, the strengthening role played by carbides, other precipitates, or dispersoids, has been experimentally investigated in the temperature range of $675-750{ }^{\circ} \mathrm{C}$ by Gobbi et al. [12] in the case of alloys VAT 32 and VAT 36. In the gamma prime-containing Ni-base superalloys, the creep resistance at high temperature is also affected by the presence of solute atoms in solid solution. In their paper, Gao et al. [13], by three-dimensional (3D) discrete dislocation dynamics simulations, proved that solute atoms such as Re and W affect dislocation glide and climb differently, and thus the back stress on dislocation motion. The different effects of these elements and their concentration as solute atoms on creep deformation resistance have also been proven.

The role played by alloy microstructure on creep deformation and creep resistance of other alloyclasses has also been experimentally investigated and modelled in scientific works included in the present Issue. Dobes et al. [14] focused on the effect of $\mathrm{Nb}$ to Fe-27 at. \% Al alloy which, by modifying the microstructure, also acts on the creep behavior, as demonstrated experimentally in the temperature range of $650-900{ }^{\circ} \mathrm{C}$.

\section{Conclusions}

The Special Issue, "Creep and High Temperature Deformation of Metals and Alloys", includes papers covering in innovative ways the relevant topics and materials in the field. The Guest Editors are aware of the quality of the contributions and of their inspiring potential for scientists and technicians who deal with materials facing creep during service. As a matter of fact, even if the specific materials, testing/modelling conditions, and microstructures have been addressed by these contributions, further innovative approaches and studies can take their cue from them.

Acknowledgments: The Guest Editors thank all who contributed effectively to the development of this Special Issue. Thanks to the authors who submitted manuscripts to share results of their research activities, and to the reviewers who agreed to read them and gave suggestions to improve their final quality. Thanks to the Editors and to Assistant Editor Kinsee Guo as well as to all the staff of the Metals Editorial Office for their management and practical support in the publication process of the Issue.

Conflicts of Interest: The authors decline conflict of interest.

\section{References}

1. Hosseinzadeh Delandar, A.; Sandström, R.; Korzhavyi, P. The Role of Glide during Creep of Copper at Low Temperatures. Metals 2018, 8, 772. [CrossRef]

2. Kassner, M.E. Application of the Taylor Equation to Five-Power-Law Creep Considering the Influence of Solutes. Metals 2018, 8, 813. [CrossRef]

3. Xu, Q.; Tu, J.; Lu, Z. Development of the FE In-House Procedure for Creep Damage Simulation at Grain Boundary Level. Metals 2019, 9, 656. [CrossRef] 
4. Jazaeri, H.; Bouchard, P.J.; Hutchings, M.T.; Spindler, M.W.; Mamun, A.A.; Heenan, R.K. An Investigation into Creep Cavity Development in 316H Stainless Steel. Metals 2019, 9, 318. [CrossRef]

5. Liu, D.; Li, Y.; Xie, X.; Liang, G.; Zhao, J. Estimating the Influences of Prior Residual Stress on the Creep Rupture Mechanism for P92 Steel. Metals 2019, 9, 639. [CrossRef]

6. Holdsworth, S. Creep-Ductility of High Temperature Steels: A Review. Metals 2019, 9, 342. [CrossRef]

7. Giese, S.; Neumeier, S.; Bergholz, J.; Naumenko, D.; Quadakkers, W.J.; Vaßen, R.; Göken, M. Influence of Different Annealing Atmospheres on the Mechanical Properties of Freestanding MCrAlY Bond Coats Investigated by Micro-Tensile Creep Tests. Metals 2019, 9, 692. [CrossRef]

8. Ding, Z.Y.; Song, Y.X.; Ma, Y.; Huang, X.W.; Zhang, T.H. Nanoindentation Investigation on the Size-Dependent Creep Behavior in a Zr-Cu-Ag-Al Bulk Metallic Glass. Metals 2019, 9, 613. [CrossRef]

9. Jo, B.; Okamoto, K.; Kasahara, N. Creep Buckling of 304 Stainless-Steel Tubes Subjected to External Pressure for Nuclear Power Plant Applications. Metals 2019, 9, 536. [CrossRef]

10. Jürgens, M.; Olbricht, J.; Fedelich, B.; Skrotzki, B. Low Cycle Fatigue and Relaxation Performance of Ferritic-Martensitic Grade P92 Steel. Metals 2019, 9, 99. [CrossRef]

11. Wu, H.-W.; Wu, T.-J.; Shiue, R.-K.; Tsay, L.-W. The Effect of Normalizing Temperature on the Short-Term Creep Rupture of the Simulated HAZ in Gr.91 Steel Welds. Metals 2018, 8, 1072. [CrossRef]

12. Gobbi, V.J.; Gobbi, S.J.; Reis, D.A.P.; Ferreira, J.L.A.; Araújo, J.A.; Moreira da Silva, C.R. Creep Behaviour and Microstructural Characterization of VAT 36 and VAT 32 Superalloys. Metals 2018, 8, 877. [CrossRef]

13. Gao, S.; Yang, Z.; Grabowski, M.; Rogal, J.; Drautz, R.; Hartmaier, A. Influence of Excess Volumes Induced by Re and $W$ on Dislocation Motion and Creep in Ni-Base Single Crystal Superalloys: A 3D Discrete Dislocation Dynamics Study. Metals 2019, 9, 637. [CrossRef]

14. Dobeš, F.; Dymáček, P.; Friák, M. The Influence of Niobium Additions on Creep Resistance of Fe-27 at. \% $\mathrm{Al}$ Alloys. Metals 2019, 9, 739. [CrossRef]

(C) 2019 by the authors. Licensee MDPI, Basel, Switzerland. This article is an open access article distributed under the terms and conditions of the Creative Commons Attribution (CC BY) license (http://creativecommons.org/licenses/by/4.0/). 